\title{
Fitossociologia de Plantas Daninhas em Sistemas de INTEGRAÇÃo DE SORGO COM BRAQUIÁRIA SOB DIFERENTES FORMAS DE IMPlantaÇÃo DA PASTAGem ${ }^{1}$
}

\author{
Phytosociology of Weeds in Sorghum-Brachiaria Integration Systems under Different Forms of \\ Pasture Deployment
}

\author{
MACHADO, V.D. ${ }^{2}$, TUFFI SANTOS, L.D. ${ }^{3}$, SANTOS JR., A. ${ }^{4}$, MOTA, V.A. ${ }^{5}$, PADILHA, S.V. ${ }^{6}$ e \\ SANTOS, M.V.7
}

\begin{abstract}
RESUMO - Objetivou-se no presente trabalho avaliar o efeito da modalidade de semeadura de Brachiaria brizantha cv. Xaraés sobre a comunidade de plantas daninhas e a produtividade de Sorghum bicolor cv. BRS 160 no sistema de integração lavoura-pecuária. Os tratamentos foram constituídos da seguinte maneira: consórcio sorgo forrageiro com braquiária semeada a lanço com incorporação leve e sem incorporação; consórcio sorgo forrageiro com braquiária semeada em linha única e em duas linhas na entrelinha da cultura anual; e testemunhas, representadas pelos monocultivos de sorgo, com e sem aplicação de atrazine, e de braquiária. Maior produção de massa seca das plantas daninhas foi observada nos tratamentos em monocultivo, sendo a espécie Digitaria horizontalis a de maior valor de importância e maior cobertura do solo. Para os cultivos em consórcio, D. horizontalis obteve menores valores de importância e cobertura quando a semeadura da forrageira foi realizada a lanço com e sem incorporação. A massa seca das plantas daninhas foi semelhante entre os tratamentos consorciados e o tratamento em monocultivo de sorgo com aplicação de herbicida. As parcelas de sorgo em monocultivo que não receberam aplicação de herbicida apresentaram maior infestação de plantas daninhas. Nos consórcios não houve diferenças para os valores de massa seca de braquiária entre os tratamentos, porém as modalidades de semeadura a lanço com e sem incorporação apresentaram maiores estandes, demonstrando melhor eficiência da semeadura a lanço para a formação da pastagem. Contudo, essa forma de semeadura leva ao desenvolvimento de plantas da forrageira próximo à linha de cultivo do sorgo, o que pode comprometer a produção dessa cultura pelo aumento da competição. A forma de semeadura de $B$. brizantha interfere na produtividade do sorgo e na infestação de plantas daninhas.
\end{abstract}

Palavras-chave: consorciação, forrageira, herbicida, Brachiaria brizantha, Sorghum bicolor, integração lavourapecuária.

\begin{abstract}
The objective of this study was to evaluate the effect of the sowing modality of Brachiaria brizantha $c v$. Xaraés on the weed community and productivity of Sorghum bicolor $c v$. BRS 160 under the agricultural cattle-raising integration system. The treatments were constituted by sorghum forage intercropped with $\boldsymbol{B}$. brizantha throwing-sown with light incorporation and without incorporation; sorghum forage intercropped with $\boldsymbol{B}$. brizantha sown in a single row and in two rows in the leading row of the annual culture; and witnesses represented by the sorghum monocultures, with and without atrazine application, and of brachiaria. Major production of weed dry mass was observed in the monoculture treatments, with the species Digitaria horizontalis presenting the highest importance value and widest ground cover. For the intercropping cultivations,
\end{abstract}

Recebido para publicação em 15.9.2010 e na forma revisada em 18.2.2011.

2 Zootecnista, Mestrando do Programa de Pós-graduação em Zootecnia, Universidade Federal de Viçosa UFV, <vitordm_zootec@yahoo.com.br>; ${ }^{3}$ Engํ-Agr ${ }^{\circ}$., Professor Adjunto, Instituto de Ciências Agrárias, Universidade Federal de Minas Gerais - ICA/UFMG, <ltuffi@yahoo.com.br>; ${ }^{4}$ Acadêmico de Agronomia, ICA/UFMG, <antonio_agronomia@yahoo.com.br>; ${ }^{5}$ Eng $^{0}-$ Agr $^{\circ}$., Mestre em Agroecologia, ICA/UFMG, < veronicamotabr2000@yahoo.com.br>; ${ }^{6}$ Acadêmico de Agronomia, ICA/UFMG, <valadaomg@hotmail.com>; 7 Zootecnista, Pós-Doutoranda em Zootecnia, Universidade Federal de Viçosa, <marciavitori@hotmail.com>

Planta Daninha, Viçosa-MG, v. 29, n. 1, p. 85-95, 2011 


\begin{abstract}
D. horizontalis presented lowerimportance and coverage values when forage sowing was performed by throwing with and without incorporation. Weed dry mass was similar between the intercropping treatments and the monoculture sorghum treatment with herbicide application. The monoculture sorghum plots that did not receive herbicide application showed higherweed infestation. No differences in the brachiaria dry mass values were found between the intercropping treatments; however, the sow throwing modality with and without incorporation showed larger stands, proving a better efficiency of this modality for pasture formation. However, this sowing modality leads to the development of forage plants nearthe sorghum cultivation lines, which may compromise the production of that culture by increasing competition. The type of B. brizantha sowing interferes in sorghum productivity and weed infestation.
\end{abstract}

Keywords: intercropping, forage, herbicide, Brachiaria brizantha, Sorghum bicolor.

\section{INTRODUÇÃO}

A Integração Lavoura-Pecuária (ILP) pode ser definida como um sistema de produção em que a criação animal está intimamente associada à produção de grãos, havendo alternância dessas com a produção de forragem no mesmo ano agrícola (Paulino et al., 2006).

$\mathrm{O}$ estabelecimento da forrageira com uma cultura agronômica consorciada na ILP ocorre sob condições de competição entre as espécies de interesse, principalmente em plantio simultâneo. Os consórcios são sistemas complexos, e a forma como é realizada a semeadura dos diferentes componentes que integram o sistema, o arranjo das forrageiras, a ocorrência e a distribuição da comunidade de plantas daninhas refletem diretamente na produção. Conforme a espécie, a densidade e a distribuição das plantas daninhas na ILP, há perdas significativas, decorrentes basicamente da competição pelos recursos de crescimento, da interferência na operação de colheita e da influência negativa na qualidade do grão e da silagem (Kissmann \& Groth, 1999; Severino et al., 2006).

Os problemas decorrentes da competição excessiva entre os componentes de um sistema lavoura-pecuária e destes com as espécies daninhas podem suprimir as vantagens do sistema para com o ambiente, relatadas por Macedo (2009), e incorrer em insucessos quanto a sua formação e adoção por parte dos produtores.

Embora haja questionamentos sobre o manejo de plantas daninhas em ILP e a relação com a produtividade da cultura anual, a escolha correta da forma de semeadura dos diferentes componentes que integram o consórcio e do arranjo das forrageiras pode contribuir para o manejo cultural das plantas daninhas, reduzindo os gastos com o seu controle e, em alguns casos, eliminando a utilização de herbicidas (Severino et al., 2006).

A consorciação das forrageiras pode suprimir a emergência das plantas daninhas, em virtude da agressividade dessas espécies forrageiras após a colheita da cultura produtora de grãos (Jakelaitis et al., 2004), inclusive diminuindo o crescimento de plantas daninhas de dificil controle. Entretanto, a agressividade de forrageiras, como as do gênero Brachiaria, pode ser prejudicial à cultura anual. A competitividade imposta pelas forrageiras nos consórcios pode ser amenizada com adoção de práticas culturais, como o arranjo espacial de plantas (Oliveira, 2002), que retarda o acúmulo de massa seca por parte da forrageira, durante o período de competição interespecífica, pela aplicação de subdoses de herbicidas ou pela defasagem da semeadura da forragem em relação à cultura anual.

No caso do sorgo, importante cultura para regiões com restrições hídricas advindas da má distribuição das chuvas e do longo período de seca, há no mercado escassez de herbicidas graminicidas registrados para a cultura (Brasil, 2010). Esse fato reforça a relevância da adoção de práticas adequadas de semeadura e de arranjo das forrageiras utilizadas em sistemas de integração com essa cultura. Adicionalmente, os riscos da atividade agrícola em áreas com problemas climáticos impulsionam a busca de práticas integradas, de baixo nível tecnológico, econômicas e de fácil aplicação no campo. Elas devem ser destinadas à produção de forragem no tempo das águas e 
sua conservação para a época de escassez de volumosos - fundamental para a manutenção da produção agropecuária nessas regiões.

Objetivou-se no presente trabalho avaliar a competição da braquiária (Brachiaria brizantha cv. Xaraés) em diferentes modalidades de semeadura sobre as comunidades de plantas daninhas e a produtividade do sorgo (Sorghum bicolor) em um sistema de integração lavourapecuária.

\section{MATERIAL E MÉTODOS}

O experimento foi realizado no município de Montes Claros-MG, com longitude de $43^{\circ} 53^{\prime} \mathrm{W}$, latitude de $16^{\circ} 43^{\prime} \mathrm{S}$ e altitude de $650 \mathrm{~m}$, em condição de sequeiro, nos anos agrícolas de 2008/2009. As condições climáticas durante a realização do experimento foram medidas na estação meteorológica do INMET, localizada a aproximadamente $1 \mathrm{~km}$ da área experimental, e são apresentadas na Figura 1. Segundo a classificação de Köppen, o clima é o Aw, ou seja, Tropical de Savana, e caracteriza-se por apresentar elevadas temperaturas anuais e regime pluviométrico marcado pela ocorrência de duas estações: verão chuvoso e inverno seco.

A área experimental possui histórico de cultivo de sorgo para silagem, e as características texturais e químicas do solo são apresentadas na Tabela 1 .
O delineamento experimental utilizado foi o de blocos casualizados, com cinco repetições. Para o experimento, utilizou-se o sorgo forrageiro (Sorghum bicolor) cv. BRS 610 e Brachiaria brizantha cv. Xaraés. O sorgo forrageiro foi implantado em sistema de semeadura direta, com semeadora tratorizada (Marchesan PST PLUS ${ }^{\circledR}$ ), espaçado de $0,5 \mathrm{~m}$ entre fileiras, com população média de 250.000 plantas ha ${ }^{-1}$. A adubação de semeadura foi feita com $300 \mathrm{~kg} \mathrm{ha}^{-1}$ do formulado 0430-10, localizado sob a linha de cultivo do sorgo. $\mathrm{Na}$ condição de sequeiro, a ocorrência de um veranico prolongado impossibilitou a adubação de cobertura para cultura anual.

Os tratamentos testados foram: A - consórcio S. bicolor cv. BRS610 forrageiro com $B$. brizantha cv. Xaraés semeada a lanço; B consórcio sorgo forrageiro com Xaraés semeada a lanço com incorporação leve; C consórcio sorgo forrageiro com Xaraés semeada com matraca em duas linhas na entrelinha da cultura anual; D - consórcio sorgo forrageiro com Xaraés semeada com matraca na entrelinha da cultura anual; $\mathrm{H}$ - sorgo forrageiro em monocultivo com aplicação de $1,5 \mathrm{~kg} \mathrm{ha}^{-1}$ de atrazine; $\mathrm{S} / \mathrm{H}$ - sorgo forrageiro em monocultivo sem aplicação de herbicida; e Brach - monocultivo de Xaraés. A semeadura da forrageira foi feita duas semanas após a implantação da cultura anual, utilizando $10 \mathrm{~kg} \mathrm{ha}^{-1}$ de sementes ou $0,3 \mathrm{~g} \mathrm{~m}^{-2}$ de sementes viáveis.

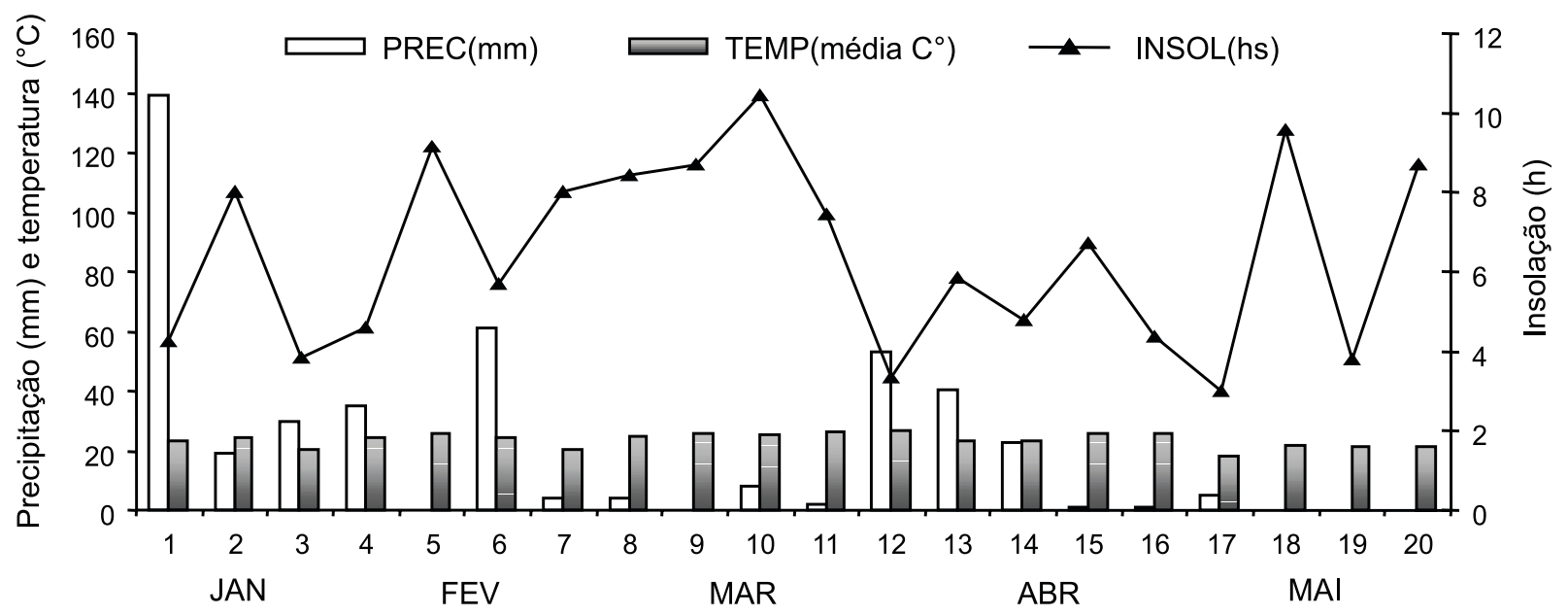

Figura 1 - Parâmetros meteorológicos de precipitação, temperatura e insolação observados durante a condução do experimento. 
Tabela 1 - Caracterização química e textural do solo da área experimental

\begin{tabular}{|c|c|c|c|c|c|c|c|}
\hline \multicolumn{8}{|c|}{ Caracterização química } \\
\hline \multirow{2}{*}{$\mathrm{pH}$} & $\mathrm{P}$ & $\mathrm{K}$ & $\mathrm{AL}$ & $\mathrm{H}+\mathrm{Al}$ & $\mathrm{Ca}$ & $\mathrm{Mg}$ & M.O. \\
\hline & \multicolumn{2}{|c|}{$\left(\mathrm{mg} \mathrm{dm}^{-3}\right)$} & \multicolumn{4}{|c|}{$\left(\mathrm{cmol}_{\mathrm{c}} \mathrm{dm}^{-3}\right)$} & $\left(\right.$ dag kg ${ }^{-1}$ \\
\hline 5,4 & 6,0 & 36 & 0,2 & 7,05 & 4,3 & 1,7 & 3,71 \\
\hline \multicolumn{8}{|c|}{ Caracterização física } \\
\hline \multicolumn{2}{|c|}{ Argila } & \multirow[t]{2}{*}{ Silte } & \multirow{2}{*}{\multicolumn{2}{|c|}{ Areia fina }} & Areia grossa & \multirow{2}{*}{\multicolumn{2}{|c|}{ Classe textural }} \\
\hline \multicolumn{3}{|c|}{$(\%)$} & & & & & \\
\hline & & 30 & 19,5 & & & \multicolumn{2}{|c|}{ Argiloso } \\
\hline
\end{tabular}

Foram consideradas como parcelas experimentais cinco fileiras de sorgo forrageiro com $4 \mathrm{~m}$ de comprimento, com cinco repetições para os tratamentos em consórcio. Cada parcela possuía área total de $8 \mathrm{~m}^{2}$ e $4 \mathrm{~m}^{2}$ de área útil, descontando-se 0,5 $\mathrm{m}$ de bordadura.

Nas parcelas de consórcio entre o sorgo forrageiro e a braquiária, independentemente da forma de semeadura desta última, bem como no monocultivo de sorgo sem herbicida, não se adotou nenhum método adicional de manejo de plantas daninhas. Nas parcelas em que o manejo de plantas daninhas foi realizado com herbicida - sorgo forrageiro em monocultivo com aplicação de $1,5 \mathrm{~kg} \mathrm{ha}^{-1}$ de atrazine utilizou-se para aplicação a formulação comercial Atrazina Nortox ${ }^{\circledR} 500$ SC. Essa operação foi realizada quando o sorgo se apresentava com cinco a sete folhas, com pulverizador tratorizado acoplado de barra contendo 19 pontas de pulverização do tipo XR110.02, espaçadas de $0,5 \mathrm{~m}$ entre si, com pressão de trabalho de $300 \mathrm{kPa}$ e volume de calda de $200 \mathrm{~L} \mathrm{ha}^{-1}$.

A amostragem da flora das plantas daninhas foi realizada nas vésperas da colheita do sorgo, quando a cultura anual apresentava teor de matéria seca recomendado para a ensilagem, por meio do método quadrado inventário proposto por Cottam \& Curtis (1956). Em cada tratamento amostraram-se cinco pontos, utilizando quadrados vazados de $1 \mathrm{~m}^{2}$ lançados ao acaso. As plantas daninhas e a braquiária, quando em consórcio, contidas na área amostrada foram devidamente identificadas in loco e comparadas com a literatura (Lorenzi, 2000), contadas, recolhidas e acondicionadas separadamente em sacos de papel. As amostras foram colocadas em estufa de circulação forçada de ar e acondicionadas a $65^{\circ} \mathrm{C}$ durante 72 horas, para determinação da massa seca da parte aérea de plantas daninhas e de forrageira.

Com os dados coletados, determinaram-se as espécies de maiores frequência e densidades e os indices fitossociológicos: densidade absoluta e relativa, frequência absoluta e relativa, abundância absoluta e relativa, dominância absoluta e relativa, valor de importância e valor de cobertura proposto por Mueller-Dombois \& Ellemberg (1974), por meio das equações:

\section{Densidade absoluta (Den abs) e relativa (Der)}

$$
\text { Den abs }=\frac{n^{o} \text { total de indivíduos por espécie }}{\text { área total coletada }}
$$

$\operatorname{Der}(\%)=\frac{\text { densidade absoluta da espécie }}{\sum \text { de densidade absoluta de todas as espécies }} \times 100$

\section{Frequência absoluta (Fre abs) e relativa}

(Fr)

$$
\begin{gathered}
\text { Fre abs }=\frac{n^{-} \text {de parcelas que contêm a espécie }}{n^{-} \text {total de parcelas utilizadas }} \\
F r=\frac{\text { Frequência absoluta da espécie }}{\sum \text { de frequência absoluta de todas as espécies }} \times 100
\end{gathered}
$$

\section{Dominância absoluta (DoA) e relativa (DoR)}

$$
D o A=\frac{\text { biomassa da espécie }}{A}
$$

$\mathrm{A}=$ área total amostrada (ha) 
DoR $=\frac{\text { biomassa da espécie }}{\sum \text { da biomassa total de todas as espécies }} \times 100$

\section{Abundância absoluta (Ab abs) e relativa (Abr)}

$$
A b a b s=\frac{n^{o} \text { total de indivíduos por espécie }}{n^{o} \text { total de parcelas que contêm a espécie }}
$$

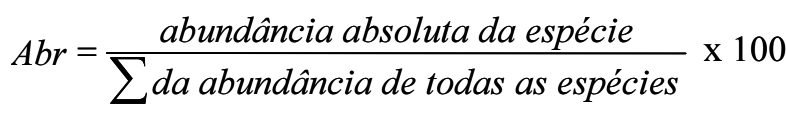

\section{Índice de valor de Importância (IVI)}

$$
\begin{gathered}
I V I=\text { frequência relativa }+ \text { dominância relativa } \\
+ \text { abundância relativa }
\end{gathered}
$$

\section{Índice de valor de Cobertura (IVC)}

$I V C=$ dominância relativa + densidade relativa

Após a amostragem das plantas daninhas e da braquiária, realizou-se a coleta do sorgo em três linhas centrais de cultivo, coletando $1 \mathrm{~m}$ linear em cada parcela. O material amostrado foi separado em panículas e folhas + colmos e posteriormente moído e levado à estufa de circulação forçada de ar, sendo acondicionado a $65^{\circ} \mathrm{C}$ durante 72 horas para a mensuração de suas massas secas.

Os dados de massa seca de panículas de sorgo, massa seca total de sorgo, massa seca de plantas daninhas, massa seca de braquiária e estande de forrageira foram submetidos à análise de variância e, quando pertinente, tiveram suas médias comparadas pelo teste de Duncan, ambos a 5\% de probabilidade.

Para determinação da eficiência dos consórcios, efetuou-se o cálculo do índice de equivalência da área (IEA), que é dado por

$$
I E A=\left(\frac{C_{S}}{M_{S}}\right)+\left(\frac{C_{F}}{M_{F}}\right)=I_{S}+I_{F},
$$

em que $\mathrm{C}_{\mathrm{S}}$ e $\mathrm{C}_{\mathrm{F}}$ são os rendimentos das culturas envolvidas em consórcio do sorgo e braquiária, respectivamente, $\mathrm{M}$ são os rendimentos dos monocultivos e $I$ os índices individuais dessas culturas, de acordo com metodologia de Willey (1979).

\section{RESULTADOS E DISCUSSÃO}

A composição da comunidade de plantas daninhas apresentou 11 espécies, e as que apresentaram maior importância (IVI) e cobertura (IVC), considerando toda a área experimental, foram: Sorghum arundinaceum (falso-massambará), Digitaria horizontalis (capim-colchão), Eleusine indica (pé-degalinha), Ipomoea spp. (corda-de-viola), Sida spp. (vassoura), Richardia brasiliensis (poaia), distribuídas em quatro famílias: Poacea, Convolvulaceae, Malvaceae e Rubiaceae.

Os dados fitossociológicos de composição e distribuição da comunidade infestante em cada tratamento são expressos na Tabela 2. Para discussão dos resultados, foram apresentadas nas tabelas todas as espécies que obtiveram IVI superior a 0,5.

Entre as espécies encontradas na área, as que registraram as maiores frequências nas áreas de consórcio de braquiária e sorgo foram $S$. arundinaceum, D. horizontalis, Eleusine indica e R. brasiliensis. Além das espécies anteriormente citadas, Ipomoea spp. e Sida spp. também apresentam elevada frequência nas áreas de monocultivo de sorgo (Tabela 2).

Em relação à abundância - parâmetro que revela as espécies que apareceram em reboleiras -, destacou-se no levantamento a espécie $D$. horizontalis, com elevados valores em todos os tratamentos (Tabela 2). Essa espécie também apresentou a maior densidade em quase todos os tratamentos (Tabela 2), refletindo na sua capacidade de ocupação da área de cultivo. $D$. horizontalis é considerada uma importante planta daninha de cultivos anuais e perenes, por apresentar elevada capacidade competitiva e tolerância a grande número de herbicidas (Pasqualeto et al., 2001; Jakelaitis et al., 2003; Dias et al., 2007). A abundância pode ser importante para indicar ações pontuais para controle da referida espécie na cultura do sorgo.

O elevado acúmulo de massa seca da parte aérea, usado no cálculo da dominância de 
Tabela 2 - Espécies e suas características fitossociológicas em cada tratamento em sistema de integração lavoura-pecuária

\begin{tabular}{|c|c|c|c|c|c|c|c|c|}
\hline Espécie & Den abs & Der $(\%)$ & Fre abs & Frr $(\%)$ & $\mathrm{Ab}$ abs & $\operatorname{Abr}(\%)$ & DoA & $\operatorname{DoR}(\%)$ \\
\hline \multicolumn{9}{|c|}{ Consórcio: Brachiaria brizantha semeada a lanço em área total } \\
\hline Eleusine indica & 5,00 & 16,00 & 0,80 & 20,00 & 6,25 & 14,01 & 2,30 & 9,59 \\
\hline Sorghum arundinaceum & 3,20 & 10,30 & 0,80 & 20,00 & 4,00 & 8,97 & 5,64 & 23,54 \\
\hline Richardia brasiliensis & 11,40 & 36,50 & 0,60 & 15,00 & 19,00 & 42,61 & 8,68 & 36,26 \\
\hline Digitaria horizontalis & 10,40 & 33,30 & 0,80 & 20,00 & 13,00 & 29,16 & 4,92 & 20,53 \\
\hline Ipomoea spp. & 0,80 & 2,56 & 0,60 & 15,00 & 1,33 & 2,99 & 2,16 & 9,03 \\
\hline Sida spp. & 0,40 & 1,28 & 0,40 & 10,00 & 1,00 & 2,24 & 0,25 & 1,03 \\
\hline \multicolumn{9}{|c|}{ Consórcio: Brachiaria brizantha semeada a lanço em área total com incorporação } \\
\hline Eleusine indica & 2,60 & 9,63 & 0,60 & 15,00 & 4,33 & 13,38 & 0,34 & 0,95 \\
\hline Sorghum arundinaceum & 2,40 & 8,89 & 0,80 & 20,00 & 3,00 & 9,26 & 12,46 & 34,60 \\
\hline Richardia brasiliensis & 4,20 & 15,55 & 0,80 & 20,00 & 5,25 & 16,21 & 4,16 & 11,54 \\
\hline Digitaria horizontalis & 15,80 & 58,52 & 1,00 & 25,00 & 15,80 & 48,79 & 12,17 & 33,80 \\
\hline Ipomoea spp. & 1,80 & 6,67 & 0,60 & 15,00 & 3,00 & 9,26 & 6,80 & 18,90 \\
\hline Sida spp. & 0,20 & 0,74 & 0,20 & 5,00 & 1,00 & 0,99 & 0,07 & 0,20 \\
\hline \multicolumn{9}{|c|}{ Consórcio: Brachiaria brizantha semeada em duas linhas nas entrelinhas do sorgo } \\
\hline Eleusine indica & 4,40 & 18,49 & 0,60 & 16,66 & 7,33 & 24,39 & 0,62 & 2,04 \\
\hline Sorghum arundinaceum & 5,00 & 21,00 & 1,00 & 27,78 & 5,00 & 16,63 & 8,61 & 28,20 \\
\hline Richardia brasiliensis & 1,40 & 5,88 & 0,60 & 16,66 & 2,33 & 7,76 & 0,92 & 3,02 \\
\hline Digitaria horizontalis & 12,40 & 52,10 & 1,00 & 27,78 & 12,40 & 41,24 & 19,75 & 64,68 \\
\hline Ipomoea spp. & 0,20 & 0,84 & 0,20 & 5,55 & 1,00 & 3,32 & 0,53 & 1,75 \\
\hline Sida spp. & 0,40 & 1,68 & 0,20 & 5,55 & 2,00 & 6,65 & 0,09 & 1,14 \\
\hline \multicolumn{9}{|c|}{ Consórcio: Brachiaria brizantha semeada nas entrelinhas do sorgo } \\
\hline Eleusine indica & 4,40 & 8,78 & 0,60 & 16,67 & 7,33 & 11,33 & 0,62 & 4,86 \\
\hline Sorghum arundinaceum & 5,00 & 10,81 & 1,00 & 22,22 & 5,00 & 10,46 & 8,61 & 16,49 \\
\hline Richardia brasiliensis & 1,40 & 12,16 & 0,60 & 16,67 & 2,33 & 15,69 & 0,92 & 13,58 \\
\hline Digitaria horizontalis & 12,40 & 62,16 & 1,00 & 27,77 & 12,40 & 48,12 & 19,75 & 47,96 \\
\hline Ipomoea spp. & 0,20 & 4,73 & 0,20 & 11,11 & 1,00 & 9,15 & 0,53 & 16,41 \\
\hline Sida spp. & 0,40 & 1,35 & 0,20 & 55,55 & 2,00 & 5,23 & 0,09 & 0,68 \\
\hline \multicolumn{9}{|c|}{ Monocultivo de Brachiaria brizantha } \\
\hline Eleusine indica & 2,33 & 12,96 & 0,40 & 20,00 & 3,50 & 17,50 & 6,65 & 6,93 \\
\hline Sorghum arundinaceum & 1,67 & 9,26 & 0,40 & 20,00 & 2,50 & 12,50 & 4,25 & 4,43 \\
\hline Richardia brasiliensis & 3,67 & 20,37 & 0,60 & 30,00 & 3,67 & 18,33 & 30,44 & 31,73 \\
\hline Digitaria horizontalis & 10,33 & 57,41 & 0,60 & 30,00 & 10,33 & 51,67 & 54,60 & 56,92 \\
\hline \multicolumn{9}{|c|}{ Monocultivo de sorgo sem aplicação de atrazine } \\
\hline Eleusine indica & 7,00 & 19,44 & 0,60 & 21,43 & 7,00 & 18,92 & 11,27 & 17,21 \\
\hline Sorghum arundinaceum & 10,33 & 28,70 & 0,60 & 21,43 & 10,33 & 27,93 & 19,10 & 29,17 \\
\hline Richardia brasiliensis & 2,00 & 5,56 & 0,40 & 14,29 & 3,00 & 8,11 & 2,71 & 4,14 \\
\hline Digitaria horizontalis & 12,33 & 34,26 & 0,60 & 21,43 & 12,33 & 33,33 & 24,24 & 37,01 \\
\hline Ipomoea spp. & 4,33 & 12,04 & 0,60 & 21,43 & 4,33 & 11,71 & 8,17 & 12,47 \\
\hline \multicolumn{9}{|c|}{ Monocultivo de sorgo com aplicação de $1,5 \mathrm{~L} \mathrm{ha}^{-1}$ de atrazine } \\
\hline Eleusine indica & 3,00 & 6,16 & 0,60 & 21,43 & 3,00 & 4,50 & 4,60 & 4,16 \\
\hline Sorghum arundinaceum & 3,67 & 7,53 & 0,60 & 21,43 & 3,67 & 5,50 & 15,24 & 13,76 \\
\hline Richardia brasiliensis & 8,67 & 17,81 & 0,20 & 7,14 & 26,00 & 39,00 & 18,96 & 17,12 \\
\hline Digitaria horizontalis & 31,33 & 64,38 & 0,60 & 21,43 & 31,33 & 47,00 & 69,80 & 63,04 \\
\hline Ipomoea spp. & 0,33 & 0,68 & 0,20 & 7,14 & 1,00 & 1,50 & 1,52 & 1,38 \\
\hline Sida spp. & 1,67 & 3,42 & 0,60 & 21,43 & 1,67 & 2,50 & 0,60 & 0,54 \\
\hline
\end{tabular}


determinadas espécies, como $S$. arundinaceum e $D$. horizontalis, nas parcelas em monocultivo, bem como o porte dessas espécies, pode ter suprimido a frequência de outras espécies (Tabela 2).

Embora a composição da comunidade de plantas daninhas em um agroecossistema esteja associada às condições edafoclimáticas da região, determinados manejos do solo e tratos culturais, como a aplicação de herbicida e o revolvimento do solo, podem favorecer ou reprimir determinada espécie (Godoy et al., 1995). Existem exemplos de inversão das importâncias relativas das espécies devido à adoção de métodos de controle (Monquero \& Christoffoleti, 2003) e à alteração no sistema de cultivo (Voll et al., 2001) ou no esquema de rotação de culturas (Buhler et al., 1997).

Comparando o comportamento entre espécies em relação aos manejos do solo, Voll et al. (2001) observaram que as gramineas tenderam a apresentar período de sobrevivência menor em semeadura direta, em relação aos demais manejos de movimentação do solo, enquanto as folhas largas mostraram período de sobrevivência maior. No entanto, para Ball (1992), a sequência cultural pode ser um fator dominante a influir no banco de sementes no solo. O uso histórico da área experimental para a cultura do sorgo e do controle com herbicidas em pós-emergência seletivo à maioria das monocotiledôneas favoreceu o estabelecimento da espécie $D$. horizontalis. Jakelaitis et al. (2003) verificaram a composição da comunidade de plantas daninhas na cultura do milho em sistema de plantio direto. Segundo esses autores, o controle químico em pôs-emergência, utilizando a mistura de nicosulfuron e atrazine, não foi eficiente para a espécie D. horizontalis. Em trabalho semelhante realizado por Pasqualeto et al. (2001) com a cultura do milho em sucessão com girassol sobre a ocorrência de plantas daninhas, $D$. horizontalis foi a espécie predominante, com $77,8 \%$ do total de massa seca de plantas daninhas.

O uso de herbicida em pós-emergência diminui os valores de importância e cobertura da espécie dicotiledônea Ipomoea spp., em relação ao tratamento sem herbicida. O atrazine, pertencente ao grupo químico das triazinas, é inibidor do fotossistema II da fotossintese e controla espécies daninhas dicotiledôneas e algumas gramineas anuais (Rodrigues \& Almeida, 2005).

No monocultivo de sorgo, $D$. horizontalis obteve alta importância, com elevada frequência e grande capacidade de acúmulo de massa seca. Em concordância com Jakelaitis et al. (2003), a aplicação de 1,5 L ha-1 não interferiu no desenvolvimento e na distribuição dessa espécie (Figura 2).

Contudo, tanto para o índice de cobertura quanto para o de importância, a braquiária Xaraés foi a espécie com maior poder competitivo nos tratamentos consorciados, suprimindo o crescimento de plantas daninhas, em especial da espécie de maior importância: D. horizontalis. Características como elevado crescimento e tolerância à acidez do solo conferem à braquiária vantagens competitivas em relação às plantas daninhas. Não obstante, Martins et al. (2006) indicaram a existência de potencial alelopático da forrageira sobre a germinação e o crescimento de plantas daninhas. Severino et al. (2006) verificaram a imposição do crescimento de braquiária e do colonião sobre o crescimento de plantas daninhas, quando consorciados com milho.

Nas parcelas em que as semeaduras da forrageira foram realizadas em uma e duas linhas na entrelinha do sorgo, $D$. horizontalis obteve os maiores índice de valor de importância e índice de valor de cobertura, seguida da braquiária, ao passo que, em parcelas com semeadura a lanço com e sem incorporação, a espécie de maior indice de valor de importância e indice de valor de cobertura foi a braquiária, seguida de $D$. horizontalis.

A semeadura da braquiária a lanço propiciou maior valor de cobertura e importância à forrageira, favorecendo sua implantação e reduzindo a participação de plantas daninhas nos valores de importância e cobertura.

Os maiores valores de importância e cobertura da braquiária observados nos tratamentos a lanço sugerem maior eficiência dessa forma de semeadura em comparação à semeadura com a matraca utilizada, que, diante do tamanho reduzido da semente da forrageira, lança ao solo um número elevado de sementes por operação, resultando em uma distribuição irregular dos indivíduos pela área 
Índice de Valor de Importância IVI

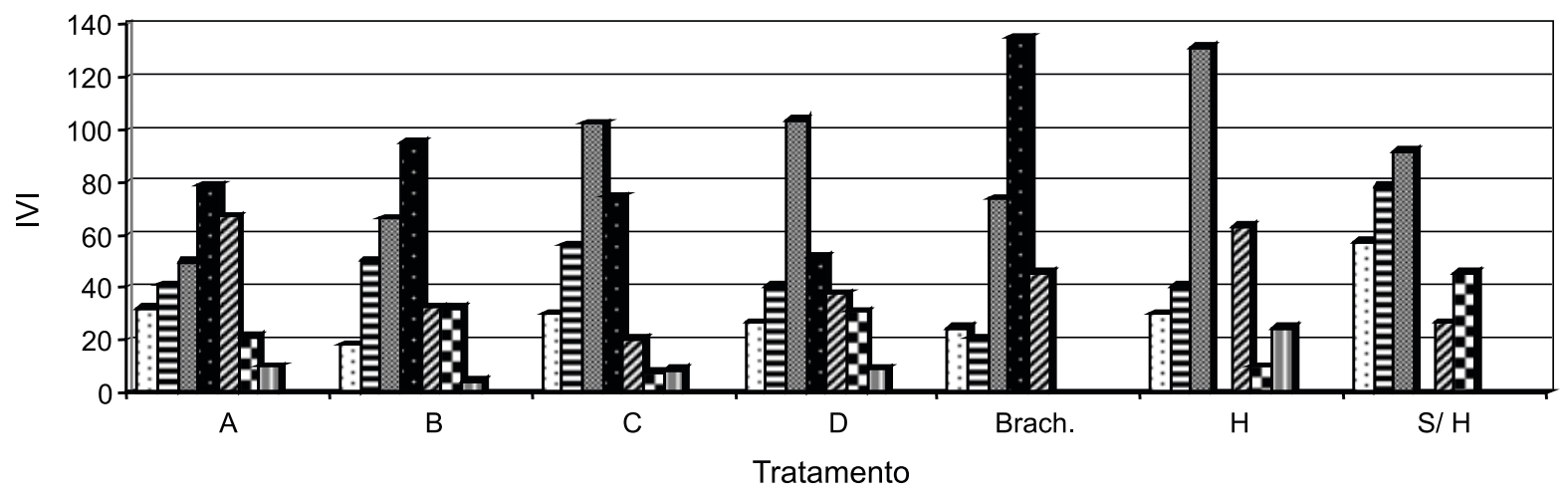

Índice de Valor de Cobertura IVC

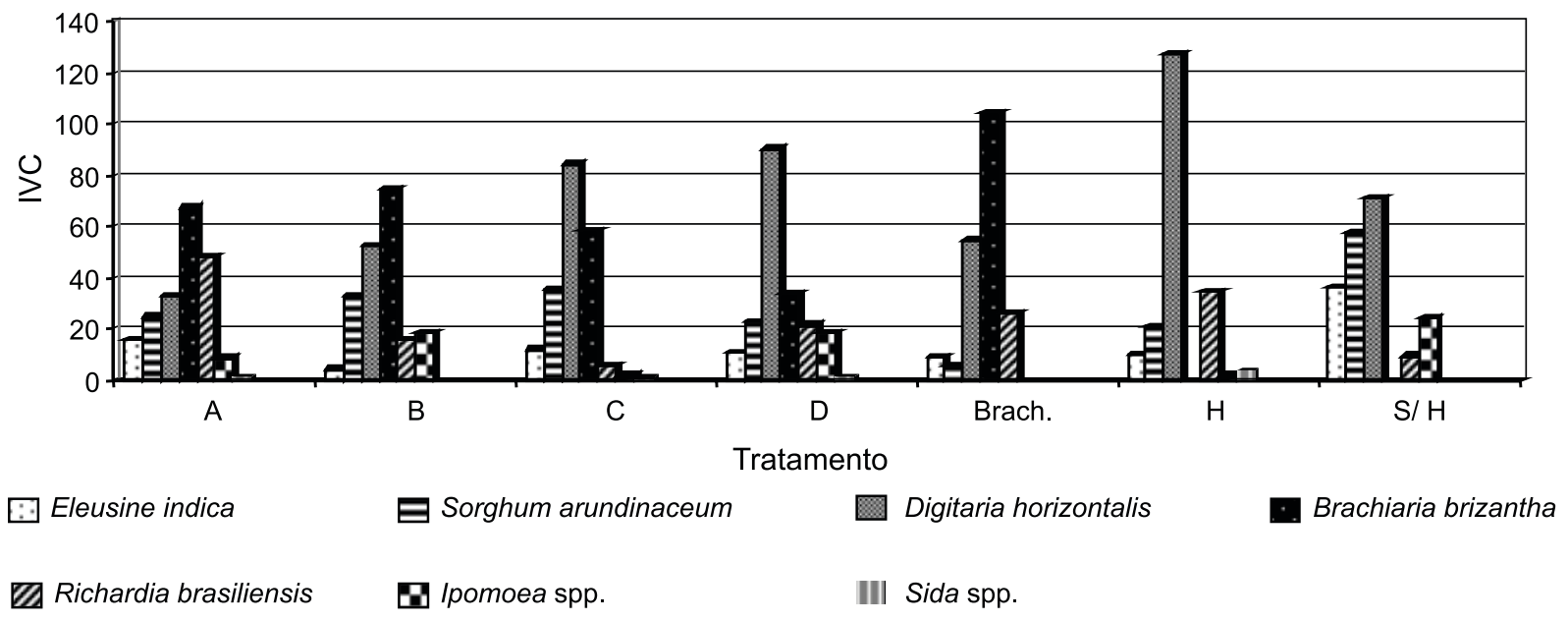

Figura 2 - Índice Cobertura do solo (IVC) e Índice de Valor de Importância (IVI) de plantas daninhas em sorgo cultivado em sistema de integração lavoura-pecuária com Brachiaria brizhanta cv. Xaraés em diferentes arranjos e semeadura da forrageira. O eixo das abscissas representa os tratamentos: A- semeadura a lanço sem incorporação; B - semeadura a lanço com leve incorporação; C semeadura dupla na entrelinha do sorgo; D - semeadura na entrelinha do sorgo; Brach. - monocultivo de braquiária; H - monocultivo de sorgo com aplicação de atrazine em pós-emergência; S/ H - monocultivo de sorgo sem aplicação de atrazine em pós-emergência.

experimental. Sugere-se misturar materiais inertes, com densidade semelhante à das sementes forrageiras, para melhorar a distribuição de sementes pequenas com a matraca.

Os tratamentos em monocultivos foram os que apresentaram maior acúmulo de biomassa da parte aérea de plantas daninhas por área. A menor competição interespecífica favoreceu o acúmulo de massa seca das espécies mais importantes dentro da comunidade de plantas daninhas (Tabela 3). Nos consórcios, a inserção de mais uma espécie de interesse intensifica a competição pelos recursos, sendo as plantas daninhas também afetadas, o que reflete em sua menor produção de biomassa. A massa das plantas daninhas foi semelhante entre os tratamentos consorciados e o tratamento em monocultivo de sorgo com aplicação de herbicida, sendo, em geral, mais elevada para parcelas em monocultivo que não receberam aplicação de herbicida (Tabela 3). Esse resultado reflete a ação do atrazine como ferramenta importante no manejo integrado de plantas daninhas para a cultura do sorgo.

A semeadura da forrageira na entrelinha da cultura do sorgo com matraca apresentou estande inferior ao das semeaduras a lanço, porém a massa seca de braquiária não diferiu 
entre as formas de semeadura, nas condições de consórcio (Tabela 3). Na formação de uma pastagem, o estande adequado é fundamental para o sucesso de implantação e para a rápida cobertura do solo. Em termos competitivos, o maior número de plantas por área significa intensificação na disputa pelos recursos, o que pode ocasionar seleção de indivíduos superiores, que irão suprimir ou mesmo eliminar outros menos adaptados ou desfavorecidos pelo ambiente. Possivelmente a competição seja um dos fatores responsáveis pela não ocorrência de maior produção nas parcelas com semeadura a lanço e com maior estande de braquiária, porém ressalta-se a importância do maior número de plantas por área de braquiária para o sucesso da formação da pastagem.

Valle et al. (2000) recomendam, para formação exclusiva de pastagens, pelo menos 15 a 20 plantas de braquiária por $\mathrm{m}^{2}$ nos primeiros 60 a 90 dias após a semeadura. As densidades populacionais das braquiárias foram superiores à recomendada pelos autores, exceto quando a braquiária foi semeada em linha única na entrelinha do sorgo (Tabela 3).

Embora a incorporação das sementes da forrageira no solo seja uma prática frequentemente recomendada para a formação de pastagens, no presente estudo, a incorporação manual não teve efeito sobre a massa seca e o estande inicial da braquiária.

A competição imposta pela cultura anual sobre a forrageira, quando semeadas em sequência, não interferiu no estande final de braquiária. Já para a variável massa seca, o sombreamento imposto pelo sorgo reduziu drasticamente o acúmulo de massa da forrageira (Tabela 3).

A baixa produtividade do sorgo encontrada em todos os tratamentos está relacionada com a baixa precipitação ocorrida durante a realização do experimento (Figura 1), a ausência da adubação de cobertura e a baixa fertilidade do solo (Tabela 1), situações frequentes na região. Entretanto, a produtividade do sorgo foi superior nos tratamentos com herbicida e na semeadura da forrageira na entrelinha, especialmente a produtividade de panícula, que foi afetada negativamente pela não aplicação de herbicida em pós-emergência e pelo estande inicial de braquiária (Tabela 3). $\mathrm{O}$ consórcio de forrageira pode ter interferido na produtividade do sorgo, sobretudo nos tratamentos a lanço, que apresentaram os maiores estandes de braquiária. Quanto ao tratamento de menor estande, a produtividade do sorgo foi semelhante à do monocultivo tradicional com aplicação de herbicida em pósemergência (Tabela 3).

Comparando os rendimentos e a eficiência do sistema consorciado e do monocultivo quando não se realizou o tratamento químico para controle de plantas daninhas em pósemergência, independentemente do método de semeadura, os sistemas consorciados foram os mais eficientes, segundo os índices de equivalência de área (IEA) (Vieira, 1984;

Tabela 3 - Comportamento produtivo de Brachiaria brizantha cv. Xaraés, sorgo forrageiro e de plantas daninhas em sistema de integração lavoura-pecuária e índice de equivalência de área (IEA) nos consórcios

\begin{tabular}{|c|c|c|c|c|c|c|}
\hline $\begin{array}{l}\text { Forma de semeadura } \\
\text { da braquiária }\end{array}$ & $\begin{array}{c}\text { Estande } \\
\text { braquiária } \\
\left(\text { plantas } \mathrm{m}^{-2}\right)\end{array}$ & $\begin{array}{c}\text { M.S. }{ }^{1 /} \\
\text { braquiária } \\
\left(\mathrm{kg} \mathrm{ha}^{-1}\right)\end{array}$ & $\begin{array}{l}\text { M.S. panícula } \\
\quad\left(\mathrm{kg} \mathrm{ha}^{-1}\right)\end{array}$ & $\begin{array}{c}\text { M.S. sorgo } \\
\text { total } \\
\left(\mathrm{kg} \mathrm{ha}^{-1}\right)\end{array}$ & $\begin{array}{c}\text { M.S. planta } \\
\text { daninha } \\
\left(\mathrm{kg} \mathrm{ha}^{-1}\right)\end{array}$ & IEA \\
\hline A lanço sem incorporação & $34,2 \mathrm{a}$ & $171,60 \mathrm{~b}$ & $1.740,10 \mathrm{~b}$ & $5.998,22 \mathrm{~b}$ & $239,40 \mathrm{~b}$ & 1,21 \\
\hline A lanço com incorporação ${ }^{2 /}$ & $35,8 \mathrm{a}$ & $239,60 \mathrm{~b}$ & $1.687,90 \mathrm{~b}$ & $6.322,96 \mathrm{~b}$ & $423,24 \mathrm{ab}$ & 1,25 \\
\hline Duas linhas $\mathrm{c} /$ matraca $^{3 /}$ & $18,2 \mathrm{ab}$ & $217,20 \mathrm{~b}$ & $2.388,94 \mathrm{~b}$ & $6.727,14 \mathrm{ab}$ & $359,62 \mathrm{~b}$ & 1,23 \\
\hline Uma linha c/ matraca $a^{3 /}$ & $9,4 \mathrm{~b}$ & $150,00 \mathrm{~b}$ & $4.465,04 \mathrm{a}$ & $9.730,64 \mathrm{a}$ & $479,72 \mathrm{ab}$ & 1,73 \\
\hline Monocultivo de braquiária & $28,8 \mathrm{ab}$ & $2.977,68 \mathrm{a}$ & - & - & - & - \\
\hline Monocultivo de sorgo s/ atrazine & - & - & $1.411,56 \mathrm{~b}$ & $5.817,04 \mathrm{~b}$ & $680,96 \mathrm{a}$ & - \\
\hline Monocultivo de sorgo c/ atrazine & - & - & $4.062,14 \mathrm{a}$ & $9.540,42 \mathrm{a}$ & $504,50 \mathrm{ab}$ & - \\
\hline $\mathrm{CV}(\%)$ & 61,34 & 24,13 & 47,36 & 30,07 & 48,63 & - \\
\hline
\end{tabular}

${ }^{1 /}$ Massa seca. ${ }^{2 /}$ Incorporação realizada com enxada. ${ }^{3 /}$ Semeadura na entrelinha do sorgo com utilização de matraca. Médias seguidas de uma mesma letra nas colunas não diferem pelo teste de Duncan a $5 \%$ de probabilidade. 
Caetano et al., 1999; Montezano \& Peil, 2006). Nessas condições, pode-se inferir pelo IEA que os sistemas consorciados foram, em geral, $35 \%$ mais eficientes que os monocultivos. No tratamento com semeadura em linha simples na entrelinha foi observado o maior rendimento, com consequente maior eficiência do uso dos recursos naturais. A produtividade do sorgo representou $96 \%$ da participação no IEA, ressaltando a importância da cultura anual na eficiência do consórcio.

Cobucci et al. (2007), trabalhando com 81 unidades experimentais de ILP com a cultura do milho, avaliaram a produtividade e a economicidade do sistema, demonstrando a sua viabilidade, desde que a produtividade do milho supere os $3.600 \mathrm{~kg} \mathrm{ha}^{-1}$.

O uso do consórcio de braquiária com sorgo, especialmente quando as sementes da forrageira são semeadas a lanço, é uma alternativa à aplicação de herbicida em pós-emergência para o controle de plantas daninhas, porém essa modalidade de semeadura pode interferir na produtividade do sorgo. A implantação da pastagem em sistema de ILP ocorre em condição adversa à forrageira; o aumento da quantidade de sementes semeadas por unidade de área pode elevar o estande inicial de braquiária Xaraés e comprometer o desempenho produtivo do sorgo.

A braquiária, quando semeada na entrelinha do sorgo, não interferiu na produtividade da cultura anual, demonstrando ser essa modalidade de semeadura a mais indicada para minimizar o efeito competitivo da forrageira sobre a cultura do sorgo em um sistema de integração lavoura-pecuária.

\section{LITERATURA CITADA}

BALL, D. A. Weed seedbank response to tillage, herbicides, and crop rotation sequence. Weed Sci., v. 40, n. 4, p. 654659, 1992.

BORGHI, E.; CRUSCIOL, C. A. C. Produtividade de milho, espaçamento e modalidade de consorciação com Brachiaria brizantha em sistema de plantio direto. Pesq. Agropec. Bras., v. 42, n. 2, p. 163-171, 2007.

BRASIL. MINISTÉRIO DA AGRICULTURA, PECUÁRIA E ABASTECIMENTO. Agrofit. 2003. Disponível em: $<$ http://agrofit.agricultura.gov.br/agrofit_cons/ principal_agrofit_cons $>2010$. Acesso em: 10 jul. 2010
BUHLER, R.; HARTZLER, R. G.; FORCELLA, F.

Implications of weed seedbank dynamics to weed management. Weed Sci., v. 45, p. 329-336, 1997.

CAETANO, L. C. S.; FERREIRA, J. M.; ARAÚJO, L. M. Produtividade de cenoura e alface em sistema de consorciação. Hortic. Bras., v. 17, n. 2, p. 143-146, 1999.

CHIESA, E. D. et al. Aspectos agronômicos de híbridos de sorgo (Sorghum bicolor L. Moench) no desempenho e economicidade de novilhos confinados. Acta Sci. Animal Sci., v. 30, n. 1, p. 67-73, 2008.

COBUCCI, T; WRUCH, F.J.; KLUTHCOUSKI, J. Opções de integração lavoura-pecuária e alguns de seus aspectos econômicos. Embrapa: Inf. Agropec., v. 28, n. 240, p. 25-42, 2007.

COTTAM, G.; CURTIS, J. T. The use of distance measures in a phytosociological sampling. Ecology, v. 37, n. 3, p. 451-460, 1956.

DIAS, A. C. R. et al. Problemática da ocorrência de diferentes espécies de capim-colchão (Digitaria spp.) na cultura da cana-de-açúcar. Planta Daninha, v. 25, n. 3, p. 489-499. 2007.

GODOY, G.; VEGA, J.; PITTY, A. El tipo de labranza afecta la flora y la distribución vertical del banco de semillas de malezas. Ceiba, v. 36, n. 2, p. 217-229, 1995.

JAKELAITIS, A. et al. Dinâmica populacional de plantas daninhas sob diferentes sistemas de manejo nas culturas de milho e feijão. Planta Daninha, v. 21, n. 1, p. 71-79, 2003

JAKELAITIS, A. et al. Manejo de plantas daninhas no consórcio de milho com capim-braquiária (Brachiaria decumbens). Planta Daninha, v. 22, n. 4 p. 553-560, 2004.

KISSMANN, K. G.; GROTH, D. Plantas infestantes e nocivas. 2.ed. São Paulo: BASF, 1999. 978 p.

KUVA, M. A. et al. Fitossociologia de comunidades de plantas daninhas em agroecossistema cana-crua. Planta Daninha, v. 25, n. 3, p. 501-511, 2007.

LORENZI, H. Manual de identificação e controle de plantas daninhas: plantio direto e convencional. 5.ed. Nova Odessa: Plantarum, 2000. 399 p.

MACEDO, M. C. M. Integração lavoura e pecuária: o estado da arte e inovações tecnológicas. R. Bras. Zootec., v. 38, p. 133-146, 2009. (Suplemento Especial).

MARTINS, D.; MARTINS, C. C.; COSTA, N. V. Potencial alelopático de soluções de solo cultivado com Brachiaria brizantha: efeitos sobre a germinação de gramíneas forrageiras e plantas daninhas de pastagens. Planta Daninha, v. 24, n. 1, p. $61-70,2006$. 
MONQUERO, P. A.; CHRISTOFFOLETI, P. J. Dinâmica do banco de sementes em áreas com aplicação freqüente do herbicida glyphosate. Planta Daninha, v. 21, n. 1, p. 63-69, 2003.

MONTEZANO, E. M.; PEIL, R. M. N. Sistema de consórcio na produção de hortaliças. R. Bras. Agroc., v. 12, n. 2 , p. 129-132, 2006.

MUELLER-DUMBOIS, D.; ELLENBERG, H. Aims and methods vegetation ecology. New York: John Wiley \& Sons, 1974.

OLIVEIRA, E. Opções de forrageiras de entressafra e inverno em sistema de integração lavoura-pecuária. In: ENCONTRO DE INTEGRAÇÃO LAVOURA-PECUÁRIA NO SUL DO BRASIL, 2002, Curitiba. Anais... Curitiba: Instituto Agronômico do Paraná, 2002. p. 327-364.

PASQUALETO, A. et al. Ocorrência de plantas daninhas na cultura do milho (Zea mays L.) em sucessão a culturas de safrinhas no sistema plantio direto. Pesq. Agropec. Trop., v. 31, n. 2 , p. $133-138,2001$

PAULINO, P. V. R. et al. Integração Lavoura-Pecuária: utilização do pasto e subprodutos. In: SIMPÓSIO DE PRODUÇÃO DE GADO DE CORTE, 5., 2006, Viçosa, MG Anais... Viçosa, MG: Universidade Federal de Viçosa, 2006. p. $157-220$
RODRIGUES, B. N.; ALMEIDA, F. S. Guia de herbicidas. 5. ed. Londrina: 2005. 592 p.

SEVERINO, F. J.; CARVALHO, S. J. P.; CRISTOFFOLETI, P. J. Interferências mútuas entre a cultura do milho, espécies forrageiras e plantas daninhas em um sistema de consorcio Implicações sobre a cultura do milho. Planta Daninha, v. 23, n. 4, p. 589-596, 2006.

VALLE, C. B.; EUCLIDES, V. P. B.; MACEDO, M. C. M. Características das plantas forrageiras do gênero Brachiaria. In: SIMPÓSIO SOBRE MANEJO DAS PASTAGENS, 2000, Piracicaba. Anais... Piracicaba: FEALQ, 2000. p. $65-108$.

VIEIRA, C. Índice de equivalência de área. Inf. Agropec., v. 10, n. 118, p. $12-13,1984$

VOLL, E. et al. Dinâmica do banco de sementes de plantas daninhas sob diferentes sistemas de manejo do solo.

Planta Daninha, v. 19, n. 2, p. 171-178, 2001.

WILLEY, R. W. Intercropping: its importance and research needs: Part 1. Competition and yield advantages. Field Crop Abstracts, v. 32, n. 1, p. 1-10, 1979. 